\title{
A Evolução do Conceito de Marketing "Verde"
}

\section{Ricardo Oselame Schiochet ricardos26@yahoo.com.br3}

Mestrado Acadêmico em Administração, Escola de Administração, Universidade Federal do Rio Grande do Sul.

\section{RESUMO}

O presente artigo tem como objetivo verificar de que forma a crescente preocupação mundial acerca de questões ambientais contribuiu para uma nova vertente no marketing, conhecida como ambiental, sustentável ou verde, e como isso está alterando a forma como as empresas gerenciam seu composto mercadológico, repensam o design de seus produtos, insumos, processos de distribuição e descarte. O objetivo deste artigo é traçar um panorama de como a teoria e o conceito de marketing verde evoluíram nos últimos anos. A relevância do tema se dá pela profusão de temas ambientais na mídia e pela mudança no perfil dos consumidores que exige das empresas a adoção de práticas ambientalmente corretas com o intuito de gerar produtos mais sustentáveis, fortalecendo sua marca e diferenciando sua imagem no mercado.

Palavras-chave: Marketing verde, marketing societal, sustentabilidade. 


\title{
The Evolution of The "Green" Marketing Concept
}

\begin{abstract}
The following paper aims to verify how the growing worldwide concern about environmental issues has contributed to a new dimension in marketing known as environmental, sustainable or green marketing and how it has been changing the way companies manage their marketing mix, rethink the design of their products, inputs, distribution and disposal processes. The objective of this paper is to outline how the theory and concept of green marketing have evolved in recent years. The relevance of the topic is due to the profusion of environmental topics in the media as well as the change in consumers' profile, which requires companies to adopt environmentally correct practices aiming the generation of more sustainable products, strengthening their brand and making them standout in the market.
\end{abstract}

Keywords: Green marketing, social marketing, sustainability.

\section{INTRODUÇÃO}

\section{Fundamentos da Responsabilidade Socioambiental}

O debate sobre a responsabilidade socioambiental das empresas, o qual dava-se de forma rara até poucas décadas atrás, tornou-se presente, seja nos ambientes corporativos, nos movimentos da sociedade civil quanto nos corredores acadêmicos. Parece haver se criado um consenso de que a empresa, assumindo seu papel de ator social influente e poderoso, deve não apenas disciplinar-se, mas também colocar-se formalmente à serviço do bem comum, de modo a remediar falhas de funcionamento do mercado e o atual encolhimento do estado (BANCO MUNDIAL, 2002).

Segundo relatório do Banco Mundial (2002) a responsabilidade socioambiental empresarial é o compromisso que as empresas devem assumir no sentido de contribuir com o desenvolvimento econômico sustentável, trabalhando de maneira conjunta com os funcionários, suas famílias, a comunidade local e a sociedade em geral com objetivo de melhorar a qualidade de vida de todos, e de uma maneira que seja boa para a empresa, para o desenvolvimento, para a sociedade e para o meio ambiente.

No entanto, este aparente consenso está longe de estender-se às soluções propriamente ditas. Friedman, por exemplo, defende que a maior responsabilidade social da empresa consiste em aumentar seus próprios lucros, o restante não passa de tolice. 
Segundo o autor, indivíduos podem ter responsabilidades, organizações não. E desde que as empresas estejam atuando de acordo com a lei, sua única função é gerar receita e aumentar o capital dos seus acionistas (FRIEDMAN, 1970).

Já Young (2004) defende que as empresas têm uma parcela de responsabilidade na solução dos problemas sociais e ambientais, em parte pois ajudaram a causar estes problemas, e também pelo fato de que detém poder político e habilidade de mobilizar recursos financeiros e tecnológicos para desenvolver ações que podem ser replicadas pelos demais atores sociais.

Lazer (1969) acredita que as empresas têm sim um papel importante na sociedade e são responsáveis pelos efeitos das suas decisões e ações, especialmente na área de marketing, e devem estar preocupadas com algo mais do que simplesmente a geração de lucro. Entretanto, o autor demonstra não acreditar na teoria de que as empresas possam ser as responsáveis pelos problemas na sociedade e que os consumidores não devem se sentir culpados pelos seus hábitos de consumo. Existe, no entanto, uma transição entre o perfil mais econômico, voltado para a lucratividade, para um perfil mais preocupado com os impactos causados na sociedade (LAZER, 1969).

Enquanto grande parte dos autores trata a responsabilidade social e ambiental como algo único, Reinhardt (1999) argumenta que a preservação do meio ambiente não deve ser vista como uma questão de responsabilidade social. Para o autor, o investimento ambiental está intrinsecamente relacionado à sustentabilidade do negócio; portanto incluir essa variável no campo da responsabilidade social levaria a empresa a ignorar determinados riscos resultantes dos problemas ambientais.

Com relação à responsabilidade socioambiental e a performance da empresa, Hart (1997) afirma que é preciso criar uma visão de economia global sustentável, ou seja, desenvolver estratégias e competências integradas com o meio ambiente, e, ao mesmo tempo, coerentes com os problemas das diferentes economias (de mercado, de sobrevivência e da natureza).

Nos próximos anos, o desenvolvimento sustentável será uma das maiores oportunidades da história dos negócios e cabe aos executivos liderar este caminho. Para Hart (1997) as empresas devem assumir o papel de educadoras, direcionando a 
preferência dos consumidores por produtos e serviços consistentes com a questão da sustentabilidade. E é exatamente nesta função de educadora que o marketing assume seu papel de protagonista.

\section{A EVOLUÇÃO DO MARKETING VERDE}

É consenso na literatura que o marketing existe desde os primórdios da humanidade. Como ciência, entretanto, nasceu por volta de 1900. Segundo Motta (1983) o marketing é uma terminologia recente de uma prática que remonta aos primórdios da troca e do comércio. Quando o conceito de marketing surge no início do século passado, ainda muito ligado à teoria econômica, ele concentrava-se no escoamento da produção e questões de distribuição física dos produtos. A partir da década de vinte, preocupa-se com as questões institucionais. Com a concepção do mix de marketing na década de cinquenta, sua orientação desloca-se para o campo gerencial. Ao longo do tempo seu conceito evolui, adaptando-se às novas realidades da produção e da sociedade (MOTTA, 1983).

Para acompanhar as mudanças sociais e no ambiente de negócios, teóricos e acadêmicos de marketing reexaminaram seu foco, suas técnicas e metas, alterando-os e adaptando-os ao longo dos anos. Marketing evolveu de situações e fenômenos atrelados a mercados de commodity para questões institucionais (produtores, atacadistas, varejista, agentes, representantes). Posteriormente, direcionou seu foco para o processo gerencial (análise, planejamento, organização e controle) e, mais adiante, para um foco social/societal (eficiência de mercado, qualidade do produto, impacto social, responsabilidade social) (KOTLER, 1972).

Sobre esta evolução na abordagem do marketing, Takas (1974) apresenta uma breve síntese a respeito de publicações que ampliaram os conhecimentos neste campo. $\mathrm{O}$ autor identificou três pontos que considerou importantes: (1) a satisfação de necessidades humanas; (2) a expansão do campo social e (3) a consideração do impacto societal das ações de marketing. Sob este ponto de vista, o marketing passou a ser considerado uma ferramenta para atingir de metas sociais como controle populacional, 
tolerância racial e etc. e suas ações não devem mais ser avaliadas somente sob a perspectiva da lucratividade, mas também do seu impacto na sociedade.

No entanto, mesmo com as discussões acerca do movimento do "consumerismo" e a crescente noção de responsabilidade social por parte dos consumidores percebe-se que o meio ambiente não foi significativamente contemplado pelo marketing até o início dos anos 70 (MENON e MENON, 1997). É à partir deste momento que se inicia um período de maior conscientização dos consumidores a respeito do efeito de suas ações sob o ambiente que os cerca, especialmente com o meio ambiente. Nesta linha, Webster (1975) define este consumidor socialmente consciente como aquele que considera as consequências sociais e ambientais do seu consumo e usa o seu poder de compra para tentar promover mudanças sociais.

Além disto, mudanças em legislações específicas exerceram um importante papel na forma como as empresas encaravam a adoção de estratégias verdes. As empresas passaram a direcionar esforços na busca por soluções que fossem menos agressivas ao meio ambiente e que, ao mesmo tempo, atendessem as novas legislações. No entanto, é importante destacar o papel de empresas que conseguiram se antecipar às mudanças legais e adaptaram alguns de seus processos antes das concorrentes, obtendo assim vantagem competitiva (PORTER e VAN DER LINDE, 1995).

É plausível acreditarmos que inicialmente as empresas que adotaram práticas sustentáveis o fizeram para responder às exigências legais, mas também por que percebiam a possibilidade de envolvimento em um escândalo ambiental como algo extremamente prejudicial para sua imagem, o que poderia representar uma desvantagem competitiva em relação aos seus concorrentes. No entanto, a sensibilidade ecológica evoluiu de tal maneira que acabou se tornando um desafio para o novo milênio.

Segundo Prahalad (2000) descontinuidade e inovação serão as chaves do sucesso para as empresas. A capacidade de reconhecer descontinuidades iminentes e aprender a inovar serão as chaves do sucesso para empresas que desejarem se manter competitivas no mercado. Dentre as capacidades essenciais que precisam ser aprendidas, a sensibilidade ambiental é uma delas. As empresas precisarão abandonar a perspectiva de somente cumprir legislações e adotar, de fato, um olhar para aproveitar novas 
oportunidades de negócios que irão surgir respeitando o meio ambiente (PRAHALAD, 2000).

Esta mudança no perfil dos consumidores frente a este novo momento da sociedade americana foi comprovada por um estudo realizado por Kassarjian (1971) no qual os consumidores eram questionados abertamente sobre os principais problemas que estariam por vir nos próximos anos. As respostas de 31\% dos entrevistados apontaram a preocupação com problemas relacionados a poluição do ar, seguido da Guerra do Vietnã e problemas com minorias. Estes resultados mostram a preocupação crescente da população americana com os problemas ambientais.

Porém, apesar desta preocupação ambiental ter crescido durante a década de 70, foi somente em 1987 que o conceito de desenvolvimento sustentável foi apresentado durante a $96^{\text {a }}$ Conferência da Comissão Mundial sobre Meio Ambiente e Desenvolvimento da ONU por meio de um relatório que ficou popularmente conhecido como "Nosso futuro comum". Neste relatório ficou definido que "o desenvolvimento sustentável é aquele que encontra as necessidades atuais sem comprometer a habilidade das futuras gerações de atenderem suas próprias necessidades" (ONU, 1987).

Conforme Cardoso (2008), apesar da preocupação com o impacto ecológico dos produtos datarem, pelo menos, do final do século XIX, foi apenas na década de 60 que os movimentos ambientalistas começaram a surgir na forma como conhecemos hoje. A partir desta data, uma nova abordagem de produção mais sustentável, novos processos de desenvolvimento de produtos e a própria forma de pensar o consumo passaram a ser encaradas de uma maneira mais amigável ao ambiente.

A preocupação ambiental ganhou força no início da década de 1990 com uma crescente demanda por produtos que danificassem menos o meio ambiente. Estudos realizados à época apontaram que metade dos consumidores europeus estava desejosa de produtos mais verdes e estavam dispostos a pagar mais por eles, aceitando inclusive uma compensação entre a performance ambiental em detrimento da qualidade funcional (PEATTIE e CRANE, 2005).

Conforme Chamorro (2003), o surgimento desta onda de consumo sustentável fez com que os consumidores passassem a não se preocupar somente com a satisfação de 
seus desejos e necessidades atuais, mas também em proteger o ambiente, o que obriga as empresas a adotarem uma nova maneira de ver e entender o marketing sob a ótica ecológica. Segundo o autor, ao optar pela adoção de uma estratégia de marketing verde a organização deve garantir que todas as suas ações envolvendo o marketing mix estejam alinhadas com a lógica sustentável.

A crescente preocupação ambiental e a demanda dos consumidores mais conscientes do impacto do seu consumo fizeram surgir o conceito de Marketing Verde, o qual aspirava equilibrar a busca por vendas e lucros, tradicionalmente o foco da área, com a necessidade de se pensar a questão ambiental e o resultado das ações da empresa na vida da sociedade (PEATTIE e CRANE, 2005).

Para Ottman (1998) o marketing verde é mais complexo que o marketing tradicional e requer novas estratégias que, efetivamente, abordem os desafios chave relacionados com a forma como se define o "verde", pensando cuidadosamente como serão desenvolvidos produtos que serão apreciados pelos consumidores e como esses diferenciais serão comunicados com credibilidade e impacto.

Na realidade o Marketing Verde pode ser considerado um dos novos campos de investigação dentro do escopo de Marketing Societal que, segundo Abratt e Sacks (1988) é uma extensão do marketing na sua dimensão substantiva, ou seja, são novos objetivos e preocupações do marketing dentro de organizações tradicionais com foco em transações de compra e venda. O foco deixa de ser o consumidor individual e a sociedade em geral passa a ser o público alvo do marketing. Em resumo, o marketing foi chamado para resolver os problemas ambientais, mas não sem antes ser identificado como um dos causadores da situação de dano ao meio ambiente.

Conforme Dias (2007) o marketing verde não tem uma data específica de constituição, no entanto, seu surgimento está associado aos encontros ocorridos mundialmente que visavam discutir assuntos ambientais e de sustentabilidade. Por outro lado, Kotler (1995) afirma que desde 1970, quando surgiram as leis de proteção ambiental nos Estados Unidos a postura das empresas começou a mudar. Se até então elas podiam emitir gases poluentes e agir como se não houvesse um meio ambiente sendo agredido, a partir de então elas não podiam mais. 
De acordo com Kotler (1995), apesar do conceito de marketing verde ter sido aceito pela AMA em 1970 foi somente em abril de 1990 que o movimento tomou força, juntamente com as atividades do dia do Planeta Terra. Houve então uma explosão de produtos e programas ecologicamente corretos, aumentando o número de empresas que passaram a lucrar com o novo perfil de consumidor preocupado com estas questões.

Com o aumento da preocupação social com a deterioração do meio ambiente, os profissionais de marketing despertaram para a necessidade e o valor de se pensar novas estratégias de negócio que fossem mais sustentáveis. Estudos mostraram que no ano de 1990 os fabricantes classificaram como "verdes" aproximadamente 10\% dos produtos que estavam lançando no mercado. Apesar de pequeno este número era mais do que o dobro do ano anterior e vinte vezes maior que número de produtos "verdes" oferecidos ao mercado em 1985 (SHETH e PARVATIYAR, 1995).

Sob o ponto de vista de Peattie e Charter (2005) a preocupação com o meio ambiente na área de marketing se deu em três fases. A primeira delas ocorreu em 1970 quando começaram a surgir dúvidas sobre o futuro ambiental mundial e por quanto tempo resistiriam os recursos naturais não renováveis. O segundo momento ocorreu em meados de 1980 quando a atenção estava voltada para as questões do consumo excessivo de alguns mercados. Por fim, a terceira fase inicia nos primórdios da década de 90 com a valorização dos princípios éticos na busca de novos modelos econômicos, sociais e mercadológicos.

Enquanto o marketing tem a função de identificar as necessidades e desejos dos consumidores, determinar mercados-alvo nos quais a empresa pode atuar e desenvolver um planejamento de produtos, serviços e programas específicos para estes mercados (KOTLER, 1999), o marketing verde consiste nas atividades designadas para facilitar qualquer tipo de troca que tenha o objetivo de satisfazer uma necessidade ou desejo, desde que a satisfação ocorra com o mínimo de impacto ao meio ambiente (POLONSKY e ROSENBERGER, 2001). Peattie e Crane (1997) definem o marketing verde como um processo de gestão holística responsável por identificar e satisfazer os desejos e necessidades dos clientes e da sociedade da maneira mais rentável e sustentável possível. 
Conforme Lampe e Gazda (1995) o marketing verde ou ambiental pode ser definido como a resposta do marketing para os efeitos ambientais negativos do design, produção, embalagem, marca, uso e disposição de bens e serviços. Para os autores, o marketing verde tem se tornado uma questão crucial para empresas que desejam transformar a questão ambiental em parte integrante de sua estratégia de negócio.

Seguindo uma lógica similar, Sheth e Parvatiyar (1995) tratam o marketing verde como marketing sustentável e desta forma o definem como uma abordagem que promove o desenvolvimento e a proteção sustentável do ecossistema. Esta definição demonstra um direcionamento em busca de fontes sustentáveis de produção, além de mostrar preocupação com a preservação de recursos naturais.

Em uma definição mais objetiva, segundo Ferrell e Pride (2001), marketing verde se refere ao desenvolvimento, aperfeiçoamento, promoção e distribuição de produtos que não agridam o meio ambiente. De acordo com este conceito, pode-se concluir que o marketing verde incorpora em todas as atividades de marketing a preocupação ambiental visando atender uma crescente demanda por produtos ecologicamente corretos.

Em outras palavras, o marketing verde é uma resposta das organizações à preocupação da sociedade com o meio ambiente e com a qualidade de vida das futuras gerações, decorrente principalmente do uso indiscriminado de recursos naturais não renováveis, da sempre iminente crise ambiental que se anuncia desde a década de 70 e da pressão de grupos organizados para que as empresas em geral melhorem seu desempenho ambiental (PALHARES, 2003).

Conforme Sheth e Parvatiyar (1995) a principal função do marketing verde é identificar e desenvolver opções de consumo para a sociedade que vão ao encontro de suas necessidades atuais sem, no entanto, sacrificar sua habilidade de atender às necessidades futuras dos consumidores. Segundo os autores, o marketing verde deve tratar de garantir a oferta de produtos e serviços que sejam "sócioecológicos" e que se tornem a primeira opção dos clientes, atendendo seus desejos e necessidades de consumo e estejam em consonância com a preservação e o cuidado com o meio ambiente (SHETH e PARVATIYAR, 1995). 
No entanto, segundo Peattie e Crane (2005) apesar de sua aceitação pela comunidade científica e do grande número de estudos desenvolvidos na área, o marketing verde parece ter falhado na sua principal função de mudar a forma como as empresas se comportavam e promover a adoção de novas estratégias em direção a um caminho mais sustentável. Segundo os autores talvez o grande problema na adoção do marketing verde tenha sido a incredulidade com que os consumidores receberam os produtos "verdes". Neste cenário de desconfiança as empresas não foram hábeis o suficiente para mudar o comportamento dos consumidores e inseri-los nesta mudança cultural.

Em um levantamento dos principais estudos realizados abordando a temática do marketing verde Palhares (2003) apresentou alguns resultados interessantes:

- Estudo realizado entre 1997 e 2003 mostrou um aumento da preocupação do consumidor brasileiro com a questão da reciclagem, economia de água e energia elétrica, e geração de resíduos;

- Estudo de Murphy, Kangun e Locander (1978), mostrou que fatores sócio demográficos influenciam a percepção dos consumidores quanto a assuntos ecológicos. Estes autores caracterizaram estes consumidores como sendo, geralmente mais jovens, com um maior nível de escolaridade e com status socioeconômico mais elevado.

- Webster (1975), no entanto, afirma que características ligadas à personalidade tem um poder de influência maior em mudar comportamentos do que as características socioeconômicas. $\mathrm{O}$ autor caracteriza o consumidor ambientalmente responsável como sendo jovem, bem-educado, de classe média e integrado à comunidade local.

- Kassarjian (1971) apresentou um estudo que mostrou que as características psicológicas têm maior influência na definição de comportamentos ambientalmente responsáveis, no entanto, elas estão intimamente ligadas às características socioeconômicas.

- Segundo Balderjahn (1988) os consumidores preocupados com questões ecológicas seriam aqueles que tem uma renda média mais alta até pelo fato destes 
produtos ainda serem mais caros que seus pares de mercado. Portanto, o consumidor desejoso de proteger a natureza precisa estar disposto a pagar mais por um produto que tenha um apelo ambiental.

- Em estudo realizado com um conjunto de 40 empresas no estado do Paraná, Lopes e Pacagnan (2014) comprovaram a tese de que apesar de estarem preocupadas com o impacto de suas ações no meio ambiente (77\% das empresas indicaram esta preocupação) apenas pouco mais de 20\% estabelecem estratégias de marketing verde em seu planejamento estratégico e somente $14 \%$ possuem uma política de orçamento específica para este fim. A grande maioria das empresas adota práticas de destinação adequada de resíduos e controle de emissão de poluentes principalmente para atender exigência legais e não como estratégia de diferenciação.

\section{CONSIDERAÇÕES FINAIS}

As questões ambientais, sem dúvida, interferem na maneira como os gestores administram as empresas. Apontadas como as principais causadoras dos problemas ambientais pelo alto volume de recursos que utiliza em seu processo produtivo e pelos resíduos sólidos gerados, as empresas estão sendo pressionadas a repensar sua postura mercadológica: os produtos devem ser ambientalmente mais saudáveis; a comunicação deve salientar as iniciativas verdes e atuar inclusive de maneira educativa para mudar o comportamento dos consumidores; a distribuição deve envolver embalagens que sejam, além de seguras, feitas com materiais reciclados e recicláveis além da opção por modais de transporte menos poluentes; e o uso de recursos, água e energia deve ser o mais racional possível. É o surgimento de uma nova maneira de pensar e fazer marketing. É pensar suas ações hoje e prever os impactos futuros. É fazer mais com menos. É o Marketing Verde!

Essa estruturação das empresas no sentido de responder às demandas impostas pela legislação, por pressão da sociedade e de grupos ambientalistas ou para atender a preferência dos consumidores mostra-se uma alternativa economicamente viável, 
inclusive desejável. Não se trata apenas de discutir se a busca pela sustentabilidade é positiva para os negócios e para a imagem da empresa. É ter a certeza de que restringir os esforços de marketing verde à comunicação e ao processo de desenvolvimento de produtos não será suficiente para atrair o consumidor "verde" e pode ter, inclusive, efeitos negativos se a empresa não mantiver uma postura coerente em todas as suas atividades.

Segundo Peattie e Crane (2005) o marketing verde ganhou força no final da década de 80 e início dos anos 90 e prometeu vultuosas revoluções na maneira como as empresas iriam gerenciar seu composto mercadológico. No entanto, após estudos, conferências e publicações, poucas mudanças são de fato percebidas. Os consumidores que tinham grandes expectativas quanto às inovações que seriam oferecidas parecem decepcionados. Produtos que foram lançados a pouco mais de 20 anos já não estão mais no mercado. E as empresas parecem preocupadas única e exclusivamente em atender exigências legais (PEATTIE e CRANE, 2005).

Seria o marketing verde mais uma das tantas promessas que acabam fadadas ao esquecimento? Seria ele um mito, uma falácia, ou uma lenda de algo que realmente poderia ter revolucionado a forma de fazer marketing, mas que acabou não sendo plenamente explorado e se tornou um modismo de época? Ou será uma profecia que indica uma mudança de postura que as empresas, cedo ou tarde, deverão adotar? Segundo Peattie e Crane (2005) a grande falha na adoção do marketing verde foi sua incapacidade em criar uma cultura de sustentabilidade que permeasse toda a organização. Segundo os autores o momento do marketing verde ainda não chegou, e, quando chegar, só terão sucesso as empresas que conseguirem internalizar a lógica sustentável na sua cultura. Somente desta forma os consumidores terão a verdadeira percepção de um "selo verde" atrelado às marcas.

No decorrer da concepção deste artigo foram percebidas duas limitações principais. Uma diz respeito ao fato de que a maior parte da literatura encontrada nos principais periódicos especializados reflete a realidade de países economicamente mais desenvolvidos e nos quais, supostamente, as empresas e os consumidores têm uma maneira diferente de pensar a questão da sustentabilidade, portanto, é preciso que se 
reconheça algumas possíveis peculiaridades brasileiras não abordadas na literatura de marketing. A segunda limitação diz respeito ao fato de a grande maioria dos estudos abordando a temática do marketing verde terem sido publicados na década de 90 e início dos anos 2000 quando o assunto estava mais em voga. Esse fato acaba limitando conclusões e generalizações trazidas para os dias atuais pois, tanto as estratégias de gestão quanto o comportamento dos consumidores podem ter mudado consideravelmente nestes últimos anos.

Por este motivo, recomenda-se que, no futuro, sejam conduzidos estudos qualitativos e quantitativos junto à empresas e consumidores brasileiros no sentido de verificar a adoção de ferramentas de marketing verde e a sensibilidade dos consumidores a estas estratégias. Isso permitiria às empresas que desejam direcionar suas atividades seguindo os princípios do desenvolvimento sustentável o dimensionamento do mercado para que possam desenvolver estratégias de apelo ecológico.

\section{REFERÊNCIAS}

ABRATT, R.; SACKS, D. The Marketing Challenge: Towards being profitable and socially responsible. Journal of Business Ethics, 7: 497-507, 1988.

BALDERJAHN, I. Personality variables and environmental attitudes as predictors of ecologically responsible consumption patterns. Journal of Business Research, Vol 17, p.51$56,1988$.

BANCO MUNDIAL. Public sector roles in strengthening corporate social responsibility: a baseline study. Washington, 2002. Disponível em: http://blogs.worldbank.org/psd/category/tags/corporate-social-responsibility Acessado em: 09/08/2017.

CARDOSO, R. Uma introdução à história do design. Editora Blucher, $3^{\text {a }}$ edição. São PauloSP, 2008.

CHAMORRO, A. El etiquetado ecológico: un análisis de su utilización como instrumento de marketing. Tese doutoral, Universidade de Extremadura, Badajoz, Espanha, 2003.

CRANE, A. Facing the backlash: green marketing and strategic re-orientation in the 1990s, Journal of Strategic Marketing, Vol. 8 No. 3, pp. 277-96, 2000.

DIAS, R. Marketing ambiental: ética, responsabilidade social e competitividade nos negócios. São Paulo: Atlas, 2007. 
FRIEDMAN, M. The social responsibility of business is to increase its profits. New York Times Magazine, Setembro, 1970.

HART, S. L. Beyond greening: strategies for a sustainable world. Harvard Business Review, Jan./Feb. 1997.

KASSARJIAN, H. H. Incorporating Ecology into marketing strategy: the case of air pollution. Journal of Marketing, Vol 35, p.61-65, 1971.

KOTLER, P.; LEVY, S.J. Broadening the concept of marketing. Journal of Marketing, Vol. 33, p. 10-15, 1969.

. A generic concept of marketing. Journal of Marketing v. 36, p.46-54, April. 1972.

. Princípios de marketing. $7^{\text {a }}$ ed. Rio de Janeiro: Qualitymark. 1995.

. Marketing para o século XXI: como criar, conquistar e dominar mercados. São Paulo: Futura, 1999.

LAMPE, M.; GAZDA, G.M. Green Marketing in Europe and the United States: an evolving business and society interface. International Business Review, Vol. 4, N. 3, p. 295-12, 1995.

LAZER, W. Marketing`s changing social relationships. Journal of Marketing, Vol. 33, p.3-9, 1969.

LOPES, V.N.; PACAGNAN, M.N. Marketing Verde e práticas socioambientais nas indústrias do Paraná. Revista de Administração da USP. Vol.49, N.1, jan/fev/mar, 2014.

MENON, A; MENON, A. Enviropreneurial marketing strategy: the emergence of corporate environmentalism as marketing strategy. Journal of Marketing, Vol 61, p. 51-67 January, 1997.

MOTTA, Paulo Cesar. Marketing: a extinção de uma disciplina. Revista de administração, V.18 (1), 1983.

MURPHY, P.E.; KANGUN, N.; LOCANDER, W.B. Environmentally concerned consumerracial variations. Journal of Marketing, October, 1978.

ORGANIZAÇÃO DAS NAÇÕES UNIDAS. Nosso Futuro Comum (1987). Disponível em: <https://nacoesunidas.org/acao/meio-ambiente/ >. Acesso em 22 de maio 2017

OTTMAN, J.A. Green marketing: opportunity for innovation. On-line ed. New York: NTCMcGrawHill, 1998. Disponível em: <www.greenmarketing.com/green_marketing_book>. Acesso em 15 de maio de 2017.

PALHARES, M.F. O impacto do marketing verde nas decisões sobre embalagens das cervejarias que operam no Brasil. Dissertação de Mestrado. Universidade de São Paulo, 2003.

PEATTIE, K.; CHARTER, M. Marketing Verde. In M.J. Baker (Org). Administração de Marketing: conceitos revistos e atualizados (pg. 517-537). Rio de Janeiro: Elsevier, 2005. 
PEATTIE, K.; CRANE, A. Green Marketing: legend, myth, farce or prophesy? Qualitative Market Research: An International Journal, v. 8. N.4, p. 357-70, 2005

POLONSKY, M.J.; ROSENBERGER, P.J. Reevaluating green marketing: a strategic approach. Business Horizons, Vol. 44, N.5, pg. 21-30, 2001.

PORTER, M. E.; VAND DER LINDE, C. Green and competitive: ending the stalemate. Harvard Business Review, p.120-134, September-October, 1995.

PRAHALAD, C.K. Os Desafios do Novo Milênio. Revista Exame, Junho. p. 126-132, 2000.

REINHARDT, F. L. Bringing the environment down to earth. Harvard Business Review, Nov./ Dec. 1999.

SHETH, J.N.; PARVATIYAR, A. Ecological imperatives and the role of marketing. In POLONSKY, M.J. and MINTU-WIMSATT, A.T. (org) Environmental Marketing: strategies, practice, theory and research. New York: The Haworth Press, 1995.

TAKAS, A. Societal Marketing: a businessman`s perspective. Journal of Marketing, Vol.38, p.2-7, 1974.

WEBSTER JR., F. E. Determining the characteristics of the socially conscious consumer. Journal of Consumer Research, Vol.2, December 1975.

YOUNG, R. Dilemmas and advances in corporate social responsibility in Brazil: the work of the Ethos institute. Natural Resources Forum, v.28, p.291-301, 2004. 